\title{
Using GIS-Based Tools for the Optimization of Solid Waste Collection and Transport: Case Study of Sfax City, Tunisia
}

\author{
Amjad Kallel, ${ }^{1,2}$ Mohamed Moncef Serbaji, ${ }^{1}$ and Moncef Zairi ${ }^{1,2}$ \\ ${ }^{1}$ Department of Geology, Sfax National School of Engineering, P.O. Box 1173, 3038 Sfax, Tunisia \\ ${ }^{2}$ Laboratoire Eau-Energie-Environnement (3E), Sfax National School of Engineering, P.O. Box 1173, 3038 Sfax, Tunisia \\ Correspondence should be addressed to Amjad Kallel; amjad.kallel@enis.rnu.tn
}

Received 20 November 2015; Accepted 17 February 2016

Academic Editor: Elsa de Sá Caetano

Copyright (c) 2016 Amjad Kallel et al. This is an open access article distributed under the Creative Commons Attribution License, which permits unrestricted use, distribution, and reproduction in any medium, provided the original work is properly cited.

\begin{abstract}
Expenditure for waste collection and transport in Tunisia constitutes $75-100 \%$ of the total solid waste management budget. In this study, optimized scenarios were developed using ArcGIS Network Analyst tool in order to improve the efficiency of waste collection and transportation in the district Cité El Habib of Sfax city, Tunisia. Geographic Information System (GIS) was created based on data collection and GPS tracking (collection route/bins position). The actual state (Scenario S0) was evaluated, and by modifying its particular parameters, other scenarios were generated and analyzed to identify optimal routes: S1, route optimized with the same working resources (change of stops sequencing only); S2, route optimized with change of vehicles; and S3, route optimized with change of collection method (vehicles and reallocation of bins). The results showed that the three scenarios guarantee savings compared to S0 in terms of collection time (14\%, 57\%, and 57\% for S1, S2, and S3, resp.) and distance (13.5\%, $13.5 \%$, and $40.5 \%$ for S1, S2, and S3, resp.). Thus, a direct impact on fuel consumption can be expected with savings of $16 \%, 20 \%$, and $48 \%$ for S1, S2, and S3, respectively, without mentioning the additional benefits related to $\mathrm{CO}_{2}$ emissions, hours of work, vehicles wear/maintenance, and so forth.
\end{abstract}

\section{Introduction}

Technological development, globalization, and population growth have accelerated the dynamics of urbanization processes in developing countries, which contributed to the generation of increasingly large quantities of solid waste (SW) in more or less concentrated areas. Therefore, problems related to solid waste management (SWM) remain at the forefront of the global environmental policy for sustainable development. Indeed, an effective SWM system is necessary to ensure better health and human security.

The process of SWM is very complex as it involves many technologies and disciplines associated with the control of generation, handling, storage, collection, transfer, transportation, processing, and disposal of SW [1]. SWM practices vary with the economical/social conditions and with the regulatory framework.

The collection/transport component is the showcase for any SWM system whose implications are straightforward to evaluate the success of the system and its costs. The operation involves the removal and transfer of waste from production or assembly points to transfer station or from transfer station to processing or to final landfill site. It is therefore the most influential and most costly component as it absorbs the biggest fraction of the budget allocated by municipalities for SWM in detriment of other operations in the waste management system $[2,3]$. The challenge is therefore to achieve optimal waste collection and transport operation (hauling, equipment, manipulation, etc.). However, the development of an optimal collection/transportation system for SW involves the determination of a number of selection criteria, which is a very complicated task for a planner to do manually. The use of Geographic Information System (GIS) is recognized as one of the most promising approaches to analyze complex spatial phenomena. GIS has been successfully employed for a wide range of applications, such as geology, protection and management of natural resources, risk management, urban planning, transportation, and various modeling aspects of the environment $[4,5]$. 
Nowadays, integrated GIS technology provides an advanced modeling framework for decision makers to analyze and simulate various problems related to SWM. Indeed, the GIS tool has been used to model various applications in waste management such as siting of transfer stations and landfill, optimizing the collection and transportation, and local forecasting of waste [7-9].

The use of spatial modeling tools and GIS for collection and transportation optimization can provide economic and environmental gains by reducing travel time, distance, fuel consumption, and pollutant emissions [10].

Several models for the collection and transport of SW have been developed based on appropriate software for route optimization. A 3D GIS modeling was used by Tavares et al. [11] in Cape Verde and helped to achieve up to $8-12 \%$ of fuel savings even by traveling a longer distance compared to the shortest path. An application on MapInfo software with the use of "test and adjustment" method for optimizing the route in the city of Can Tho, Vietnam, showed that distance and travel time can be reduced by $19 \%$ and $12 \%$, respectively, and could save $20 \%$ of fuel consumption [12]. Furthermore, the traveled distance has been reduced by 12 to $20 \%$ and the working time by $8 \%$ using the software RouteSmart ${ }^{T M}$ for the case of Northamptonshire, UK [13]. A 10\% reduction in the number of SW collection trips was achieved by Sahoo et al. [14] using the WasteRoute software in the area of Elgin, Illinois, USA. Using the software TransCAD ${ }^{\circledR}$, Moustafa et al. [15] developed the best solutions to the problem of collection/transport of SW in Alexandria, Egypt. Apaydin and Gonullu [16] used RouteViewPro ${ }^{\mathrm{TM}}$ for the city of Trabzon, Turkey, showing that $24.7 \%$ benefits in the total expenses could be granted. On the other hand, the ArcGIS Network Analyst application was used by several authors to optimize the collection and transportation of waste: Ghose et al. [17] who developed a GIS model for calculating optimal route in the state of West Bengal, India, and have shown that its application would allow colossal savings over a period of 15 years; Chalkias and Lasaridi [10] proposed various scenarios developed upon field real situation in the municipality of Nikea, Greece, allowing reductions of up to $17 \%$ for working time and $12.5 \%$ for the distance traveled.

In Tunisia, collection and transportation expenses currently amount for up to $75 \%$ of SWM total costs, most of which are spent on salaries and fuel. However, the results on the field are in most cases unsatisfactory and are the object of multiple complaints from citizens. Indeed, the choices are often taken empirically and irrationally under the effects of communal pressure and/or personal interests of decision makers. Thus, in the present work, an optimization was developed using the ArcGIS Network Analyst tool in order to improve the efficiency of the collection and transportation of waste in Cité El Habib district of Sfax city, Tunisia, by means of waste bins reallocation and optimization of vehicle routing in terms of traveled distance and operating time while taking into consideration all the required settings parameters, that is, population density, waste generation rate, bins locations, road network and traffic/circulation, collection vehicles capacity, and so forth.

\section{Background of SWM in Sfax City}

The case study in this work relates to a district in the Sfax city, which is the economic heart and the second largest city of Tunisia. It has a very disperse agglomeration with 300,000 inhabitants resulting in a density of 48 persons per hectare. The town of Sfax is divided into 7 districts: El Medina, El Boustane, Sidi Mansour, Sfax Nord, Errbadh, Merkez Chaker, and Cité El Habib (Figure 1). Each of these districts involves one or more municipal communities.

The amount of municipal SW collected by the municipality of Sfax was $74501 \mathrm{t}$ in 2010 , but it decreased to $53455 \mathrm{t}$ in 2013 due to the social and political events in the country during the last five years. Based on 2010 data, the corresponding average of collected waste is $0.68 \mathrm{~kg} / \mathrm{capita} /$ day (projected average being $0.71 \mathrm{~kg} / \mathrm{capita} /$ day). It should be pointed out that the municipal SW is characterized by a high level of organic matter $(68 \%)$ and thus a high rate of water content ranging between $65 \%$ and $70 \%$. Besides individual citizens, potential producers of waste are schools, kinder gardens (227); hospitals, clinics, drugstores, and fuel stations (118); touristic areas (4); cafes, restaurants, bakeries, and other businesses (3934); and hotels (18) and shopping centers (24).

Citizens dispose off their waste in plastic bags, plastic/metal dustbins (buckets and half steel drums), or polyethylene or metal containers of different capacity or simply in bulk left on ground (Figure 2).

The municipality of Sfax makes 400 metal waste bins of 770 -liter capacity available in some areas.

Waste collection is carried out manually and/or mechanically. The vehicles available in the municipality for the collection are 4 packer trucks of $12 \mathrm{~m}^{3}$ capacity, 14 rear-end loaded compaction trucks of $16 \mathrm{~m}^{3}$ capacity, 10 dump trucks of $7 \mathrm{t}$ capacity, 13 tractors of $5 \mathrm{~m}^{3}$ capacity, 2 pickup trucks of $3 \mathrm{~m}^{3}$, and 3 mini tractors. Multidump trucks $\left(30 \mathrm{~m}^{3}\right)$ are also available to evacuate the anarchic dumps and ensure transfer of waste to the municipal landfill.

The communal area is swept by a total of 44 circuits, including 19 circuits of collection operated by rear-end loaded compaction trucks, 15 by dump trucks, and 10 by tractors [6]. Besides, laborers carrying hand cart ensure the collection of waste from hardly accessible places and unload it into trucks at certain predefined gathering places (Figure 2(d)).

The staff ratio is about one collection agent per 600 inhabitants in the district of El Medina to reach up to one per 2200 inhabitants in the district of Merkez Chaker, knowing that the crew of each collection vehicle consists of a driver and two workers. The collected waste is split between two transfer stations before being transferred to the municipal landfill site in the absence of any source separation process or sorting at transfer stations.

Multiple expenditures (direct and indirect expenses) are required to handle one ton of waste from collection until landfilling operations. These expenses are as shown in Figure 3(a) where it is noted that the sum of salaries and equipment costs exceeds 70\%. In Figure 3(b) is presented the cost of collection and transport of one ton of waste (based on 2012 data in [6]) for the districts of Sfax city. The average is $76 \mathrm{TND} / \mathrm{t}$ (therefore an annual allowance 

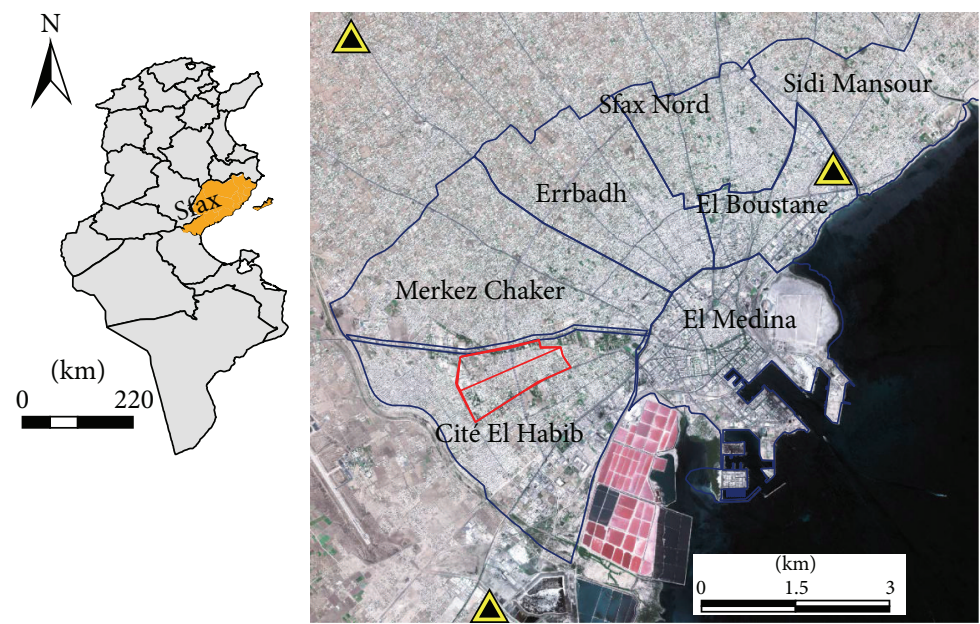

Districts of Sfax city

Study area

$\triangle$ SW transfer station

Figure 1: Sfax city and the case study area.

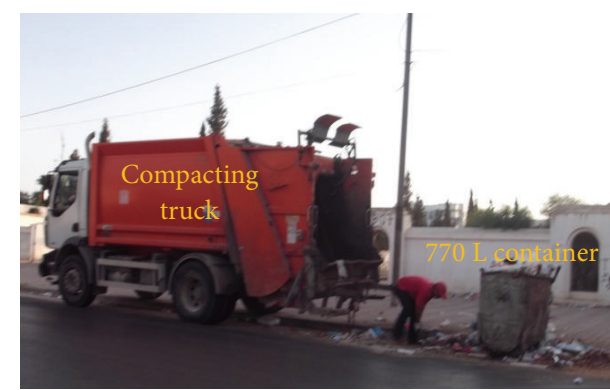

(a)

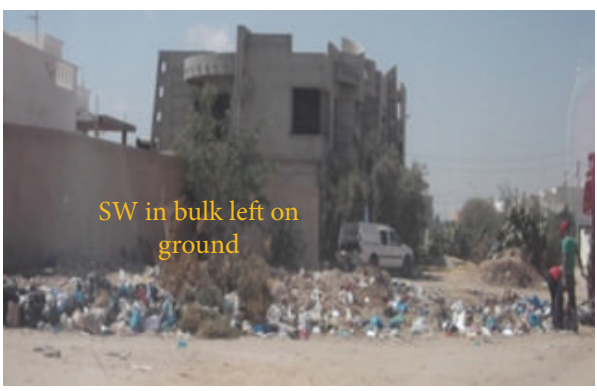

(c)

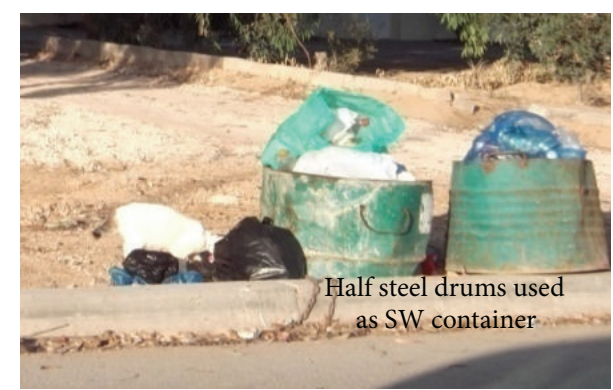

(b)

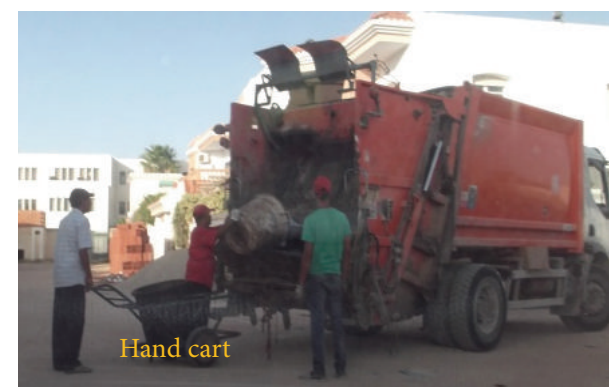

(d)

FIGURE 2: Conditions and equipment for waste collection.

per capita of around $19 \mathrm{TND} / \mathrm{cap} /$ year) showing huge gaps between different districts. On the other hand, the costs are nearly $45 \%$ lower for the districts whose collection is ensured by private companies than by municipal service, as the case of El Boustane and Sfax Nord whose costs are 41 and $51 \mathrm{TND} / \mathrm{t}$, respectively. In comparison to the national average
(53-73 TND/t) these values are excessively high and suggest that an exceptional quality of service is offered!

It should be noted that the recovery of expenses by revenues from municipal taxes does not exceed $30 \%$ and the deficit $(70 \%)$ would be borne by the state (recovery of other taxes and subsidies). 


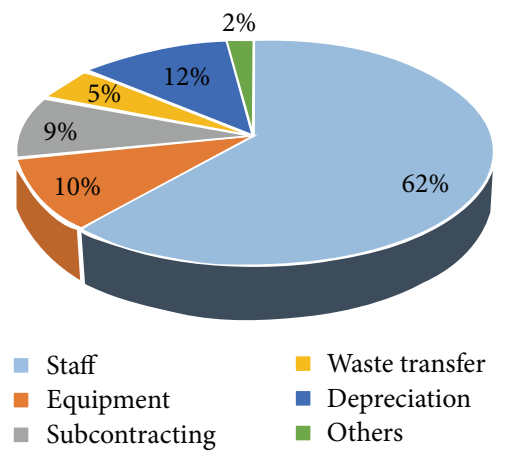

(a)

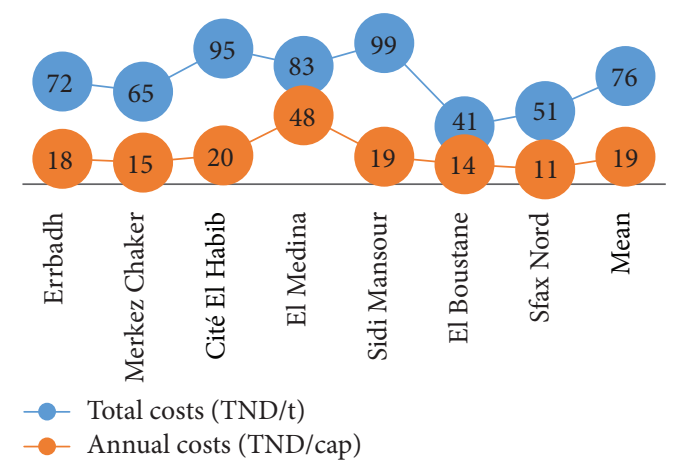

(b)

FIGURE 3: Fees and costs of SW collection/transport in the municipality of Sfax [6].

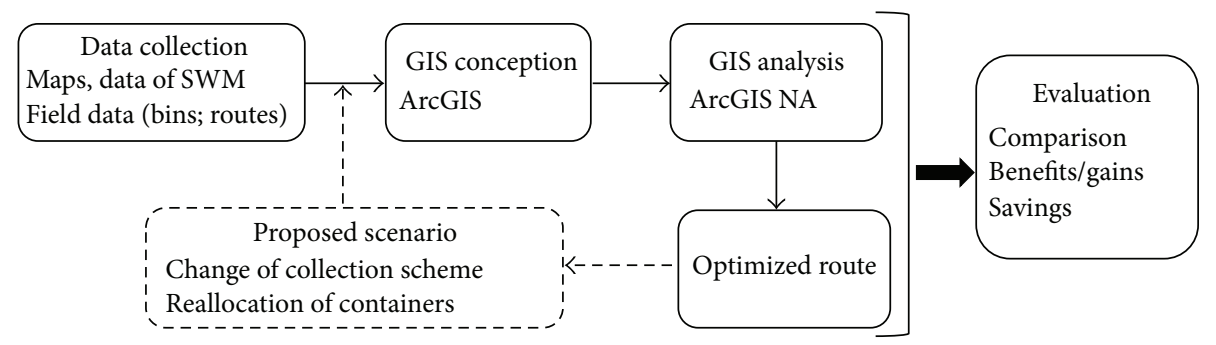

FIgURE 4: Methodology and analysis steps.

\section{Methodology and Tools}

The current case study concerns one of ten collection routes in the district Cité El Habib, Sfax city (Figure 1).

The approach for optimizing the collection system relies on GIS which provides an effective means to import, manage, and analyze spatial data. The methodology followed in this work consists mainly of two procedures (Figure 4): the design of the geodatabase and analysis of the results.

3.1. Data Collection and GIS Design. A geodatabase was prepared using the GIS environment "ESRI ArcGIS" from maps, municipal and statistical services data, satellite images, monitoring and field work, and literature data. The required data are related to geographic/urban characteristics of the study area as well as characteristics of the waste collection procedure.

The following data were obtained and processed in suitable forms (vectors, tables, and raster): delimitation of the study area; detailed land use plan of the municipality; population distribution and density; satellite image (Google Earth); road network; and information on roads (traffic, restrictions, and signs).

We have been tracking the collection route with a GPS (Global Positioning System) to take all relevant data and facts: location of the starting point, starting time, number of workers, itinerary and coordinates of collection points, condition of waste on site, condition of container and bins, odometer reading before departure and after collection, time of arrival at the transfer station, amount of waste collected, and quantity of energy consumed.

Once our database is established, the optimization model is performed with the use of the Network Analyst (NA) tool on ArcGIS. This work was carried out considering the actual scheme of collection and transportation as well as other proposed scenarios.

3.2. GIS Analyses: ArcGIS NA. ArcGIS NA is a user-friendly powerful ArcGIS extension that provides easily and directly the most efficient route solutions. The optimal path searching algorithm solves the problem of selecting the optimal route on a nonnegative weighted undirected graph in a reasonable computing time. This is mainly to build a cost matrix containing costs (length) between origins and destinations. These points correspond to pairs of vehicle stop point (location of the bins) [10].

In ArcGIS NA, routes can be calculated according to the distance and time criteria where total travel time is the sum of the vehicle operating time plus the time of waste loading/unloading.

The user is able to set or modify all the dynamic factors needed to create an initial scenario. By changing these particular parameters, other scenarios can be generated leading to several solutions. Finally, the solution is identified by a function that refers to various parameters, such as the shortest distance, the road network, and the social and environmental implications [18]. 
TABLE 1: Results for analyzed scenarios.

\begin{tabular}{lccccccc}
\hline Scenarios & Transport equipment & Workers & Traveled distance $[\mathrm{km}]$ & Duration of collection [h] & Fuel consumption [L] \\
\hline $\mathrm{S}_{0}$ & $\begin{array}{c}1 \text { truck } \\
2 \text { hand carts }\end{array}$ & 5 & $\begin{array}{c}37 \\
\text { undefined }\end{array}$ & 37 & 7 & 7 & 25 \\
\hline $\mathrm{S}_{1}$ & $\begin{array}{c}1 \text { truck } \\
2 \text { hand carts }\end{array}$ & 5 & $\begin{array}{c}32 \\
\text { undefined }\end{array}$ & 32 & 6 & 25 \\
\hline $\mathrm{S}_{2}$ & $\begin{array}{c}1 \text { truck } \\
1 \text { tractor }\end{array}$ & 6 & 19 & 32 & 2 & 6 & 21 \\
\hline $\mathrm{S}_{3}$ & 1 truck & 3 & 22 & 22 & 3 & 3 & 13 \\
\hline
\end{tabular}

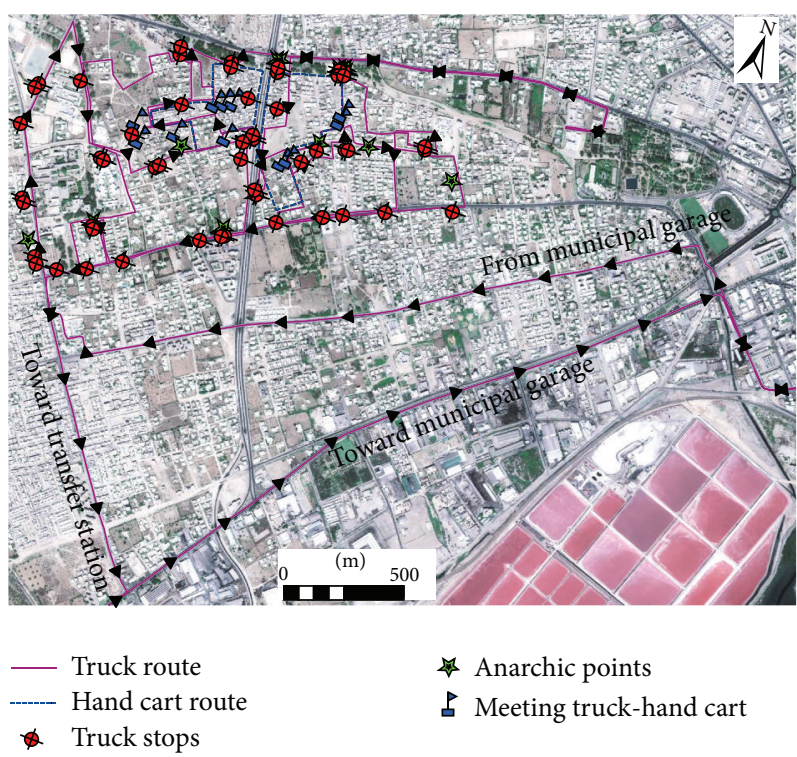

FIGURE 5: Current collection route (Scenario S0).

\section{Results and Discussion}

The current study for the chosen collection route is based on the actual real state (initial scenario, S0) along with three other suggested scenarios (S1, S2, and S3). The main results of analyses are shown in Table 1.

4.1. Scenario S0: Current Route. In Figure 5 we illustrate the tracing of journey made by rear-end loaded compaction trucks during collection, the meeting places of the truck with hand cart, and anarchic points that show waste accumulation areas. The collection is made by a team of 5 persons: the driver and two collectors in the truck and two collectors with hand cart. The distance traveled by truck from the starting point (the municipal garage) to the transfer station is $37 \mathrm{~km}$ and lasts 7 hours including 2.5 hours of driving, 4 hours to load/unload bins, and $30 \mathrm{~min}$ break. The amount of waste collected during a trip is around 3 to 5 tons.

4.2. Scenario S1: Optimized Route Using the Same Work Method. For this scenario we kept the same work method as in S0 (equipment and number of workers) and therefore the same stop points. Only the route and the sequencing of stoppages differ.

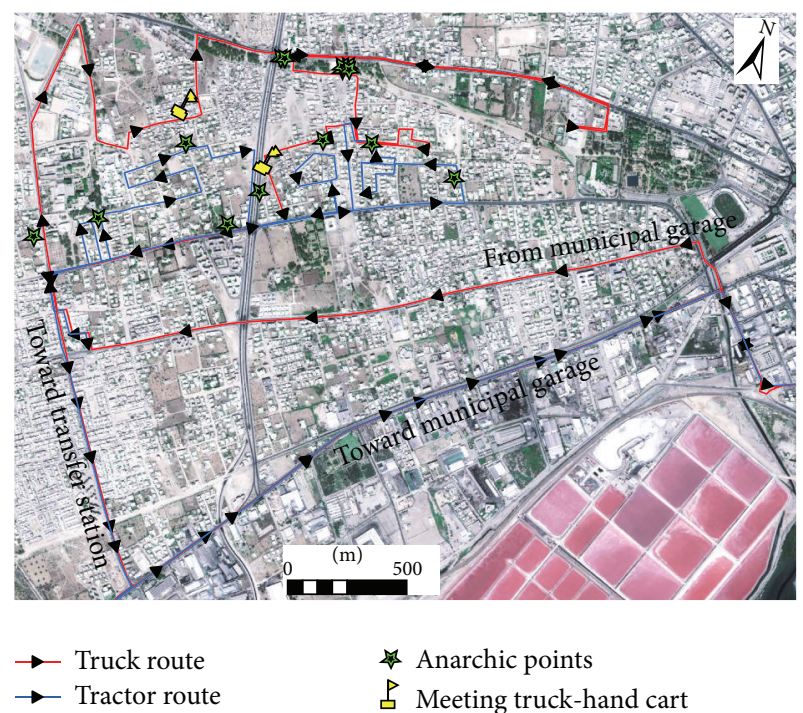

FIGURE 6: Optimized route for Scenario S2.

The truck goes through all the anarchic points and it meets with hand cart allowing the workers enough time to collect the waste from those areas as well. The driver should not backtrack in order to minimize the risks of accident. The vehicle does not pass twice through the same route.

We notice, though with the same equipment and the same staff, that waste collection is performed with decreased distance $(31 \mathrm{~km})$ and therefore with less fuel consumption $(21 \mathrm{~L})$ and less working hours (6 hours).

4.3. Scenario S2: Optimized Route with a Change of Vehicles. The passage of rear-end loaded compaction truck in tight areas hinders traffic. Besides, it is not cost effective to carry out door to door waste collection with such a vehicle. Therefore, we proposed the use of a tractor or pickup trucktype vehicle (Figure 6).

For this scenario the work will be divided into a part made by compaction truck and the other by the tractor or pickup as the following instructions:

(i) zones with large quantity of waste must be collected by the compaction truck besides collection ensured with hand cart;

(ii) zones with low quantity of waste will be collected door to door by the tractor; 
(iii) the path made by the compaction truck does not overlap that performed by the tractor as shown in Figure 6;

(iv) truck meets the hand cart only twice;

(v) residents in areas not covered by hand cart should be informed so that they carry their waste until the placed containers.

We found out that the travel distances of the truck and the tractor are short $(19 \mathrm{~km}$ and $13 \mathrm{~km}$, resp.), so this allows increasing the perimeter of working area performed by the same team for the same working session.

4.4. Scenario S3: Optimized Route with Modified Collection Method. This scenario consists of an optimized path with a modified collection mode, that is, change of vehicle and reallocation of waste bins. This scenario assumes enough containers and imperatively requires the cooperation of citizens to make the effort of bringing their waste until allocated containers.

The number of containers to put is proportional to the daily production of waste and has to be enough to serve the entire population as follows:

Total number of containers

$$
\geq \frac{\text { total SW }}{(\text { SW density } \times \text { container capacity })} \text {. }
$$

The proximity distance to container is assumed to be $125 \mathrm{~m}$; that is, the furthest citizen in a container buffer zone will walk a maximum distance of $125 \mathrm{~m}$. We considered an average waste density of $0.4 \mathrm{t} / \mathrm{m}^{3}$ and $0.77 \mathrm{~m}^{3}$ capacity containers. Collection points were selected based on the availability of sufficient space for the containers placement. The number of locations/points was deducted from a prepared map of waste production distribution by area (Figure 7). The result so obtained empirically allows covering about $92 \%$ of the whole study area and suggests that citizens living outside the covered area have to walk for more than $125 \mathrm{~m}$ to reach the nearest container. However, a better result is obtainable if an appropriate optimization of containers number/location/buffer zone is carried out.

The optimization of this scenario (Figure 8) will allow a better service and might contribute to eradicating anarchic points. In addition to that, it results in significant gains for the collection/transportation operation with reductions of $40 \%$, $57 \%, 40.5 \%$, and $48 \%$ in the number of workers, working time, traveled distance, and fuel consumption, respectively, without mentioning the extra benefits related to $\mathrm{CO}_{2}$ emissions, wear/maintenance of vehicle, and so forth.

Considering the main components of the direct charge to the cost of collection/transport of waste (vehicles expenses, drivers and collecting workers expenses), the savings rise up to $40 \mathrm{TND} / \mathrm{t}$; hence the management cost of one ton of waste may drop from $95 \mathrm{TND} / \mathrm{t}$ to around $55 \mathrm{TND} / \mathrm{t}$.

We can estimate the annual earnings in the order of $60,000 \mathrm{TND} /$ year after optimization with just an investment of about 14,000 TND for granting sufficient number (40) of containers.

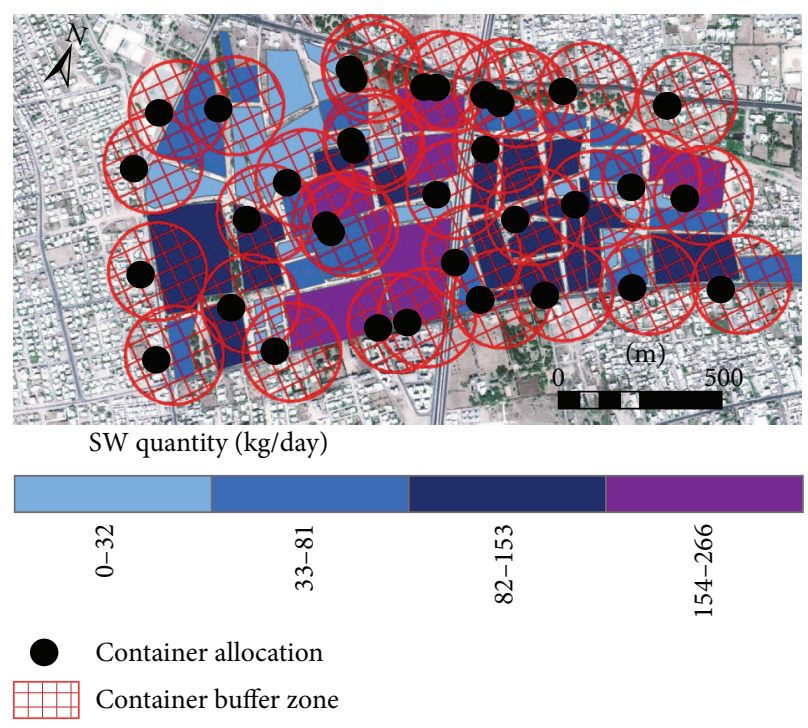

FIGURE 7: Quantity of waste produced by neighborhood and location of containers.

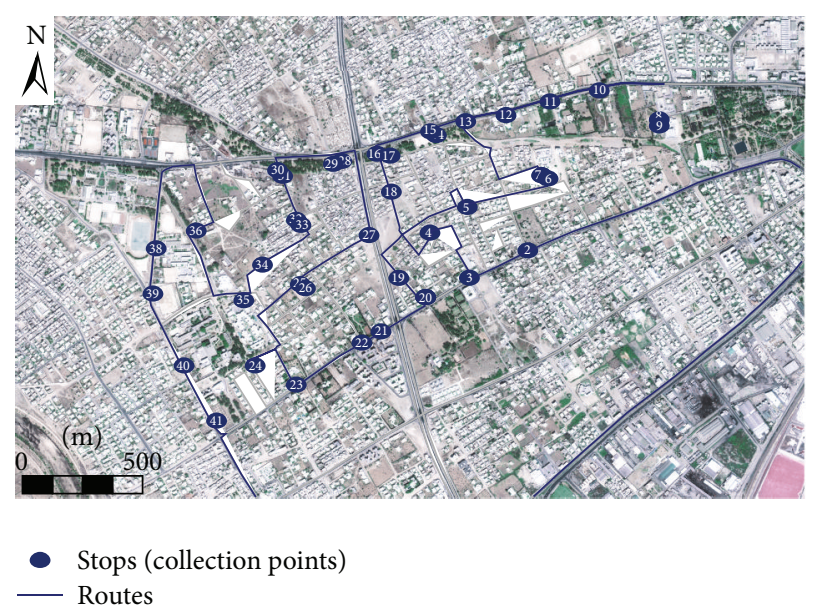

FIGURE 8: Optimized route for Scenario S3.

\section{Conclusions}

In this study, an optimization was developed using the ArcGIS NA tool in order to improve the efficiency of the collection and transportation of waste in the Cité El Habib district of the municipality of Sfax, Tunisia.

Three scenarios were generated and analyzed for the identification of optimal routes: S1-optimized route using the same work devices (change of sequencing stops only); S2-optimized route with change of vehicles; and S3optimized route with a change of collection mode (changing the transportation equipment and reallocation of containers).

Compared to the current situation, the results showed that Scenario S3 allows savings of about $40 \%, 57 \%, 40.5 \%$, and $48 \%$ in the number of workers, working time, traveled distance, and fuel consumption, respectively, and hence a gain of about $60,000 \mathrm{TND} /$ year, in addition to other benefits related to $\mathrm{CO}_{2}$ emissions, hours of work, vehicles wear/maintenance, 
and so forth. These findings indicate that GIS-based optimized scenarios can provide significant improvements to the collection/transportation system of SW and consequently to its financial and environmental costs.

These results could be further enhanced by optimizing the location of containers and subsequently this could be tried to be applied for the whole city of Sfax.

\section{Competing Interests}

The authors declare that they have no competing interests.

\section{Acknowledgments}

The authors would like to thank the Department of Environment and Cleanliness, Municipality of Sfax, for their help in providing data and for their cooperation and logistic support during fieldwork.

\section{References}

[1] G. Tchobanoglous and F. Kreith, Handbook of Solid Waste Management, McGraw-Hill, New York, NY, USA, 2nd edition, 2002.

[2] J. M. Balet, Aide-Mémoire Gestion des Déchets, Dunod, Paris, France, 2005 (French).

[3] SWEEP-NET/GIZ, "Rapport sur la gestion des déchets solides en Tunisie. Réseau régional d'échange d'informations et d'expertises dans le secteur des déchets solides dans les pays du Maghreb et du Machreq," 2014 (French).

[4] A. J. Brimicombe, "A variable resolution approach to cluster discovery in spatial data mining," in Computational Science and Its Applications-ICCSA 2003: International Conference Montreal, Canada, May 18-21, 2003 Proceedings, Part III, vol. 2669 of Lecture Notes in Computer Science, pp. 1-11, Springer, Berlin, Germany, 2003.

[5] D. J. Unwin, "GIS, spatial analysis and spatial statistics," Progress in Human Geography, vol. 20, no. 4, pp. 540-551, 1996.

[6] Gouvernorat de Sfax, "Plan communal de gestion des déchetsrapport de synthèse générale aspects techniques et analyse des couts," Report, 2013 (French).

[7] D. Khan and S. R. Samadder, "Municipal solid waste management using Geographical Information System aided methods: a mini review," Waste Management \& Research, vol. 32, no. 11, pp. 1049-1062, 2014.

[8] C. A. Arribas, C. A. Blazquez, and A. Lamas, "Urban solid waste collection system using mathematical modelling and tools of geographic information systems," Waste Management \& Research, vol. 28, no. 4, pp. 355-363, 2010.

[9] B. Dyson and N.-B. Chang, "Forecasting municipal solid waste generation in a fast-growing urban region with system dynamics modeling," Waste Management, vol. 25, no. 7, pp. 669-679, 2005.

[10] C. Chalkias and K. Lasaridi, "A GIS based model for the optimisation of municipal solid waste collection: the case study of Nikea, Athens, Greece," WSEAS Transactions on Environment and Development, vol. 5, no. 10, pp. 640-650, 2009.

[11] G. Tavares, Z. Zsigraiova, V. Semiao, and M. G. Carvalho, "Optimisation of MSW collection routes for minimum fuel consumption using 3D GIS modelling," Waste Management, vol. 29, no. 3, pp. 1176-1185, 2009.

[12] N. P. Thanh, Y. Matsui, N. V. C. Ngan, N. H. Trung, T. Q. Vinh, and N. T. H. Yen, "GIS application for estimating the current status and improvement on municipal solid waste collection and transport system: case study at can tho city, Vietnam," Asian Journal on Energy and Environment, vol. 10, pp. 108-112, 2009.

[13] P. N. O Crick and J. Holtgis, "Optimisation of household waste collection in seven districts," in Proceedings of the Waste: Waste and Resource Management, London, UK, September 2008.

[14] S. Sahoo, S. Kim, B.-I. Kim, B. Kraas, and A. Popov Jr., "Routing optimization for Waste Management," Interfaces, vol. 35, no. 1, pp. 24-36, 2005.

[15] A. Moustafa, A. A. Abdelhalim, A. B. Eltawil, and N. Fors, "Waste collection vehicle routing problem: case study in Alexandria, Egypt," in Proceedings of the 19th International Conference on Industrial Engineering and Engineering Management, pp. 935-944, October 2012.

[16] O. Apaydin and M. T. Gonullu, "Route optimization for solid waste collection: trabzon (Turkey) case study," Global NEST Journal, vol. 9, pp. 6-11, 2007.

[17] M. K. Ghose, A. K. Dikshit, and S. K. Sharma, "A GIS based transportation model for solid waste disposal-a case study on Asansol municipality," Waste Management, vol. 26, no. 11, pp. 1287-1293, 2006

[18] N. V. Karadimas, N. Doukas, M. Kolokathi, and G. Defteraiou, "Routing optimisation heuristics algorithms for urban solid waste transportation management," WSEAS Transactions on Computers, vol. 7, no. 12, pp. 2022-2031, 2008. 


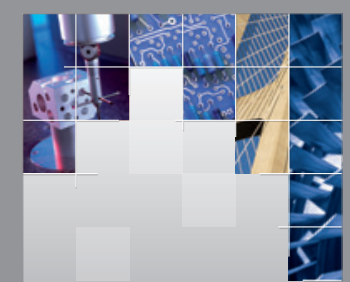

\section{Enfincering}
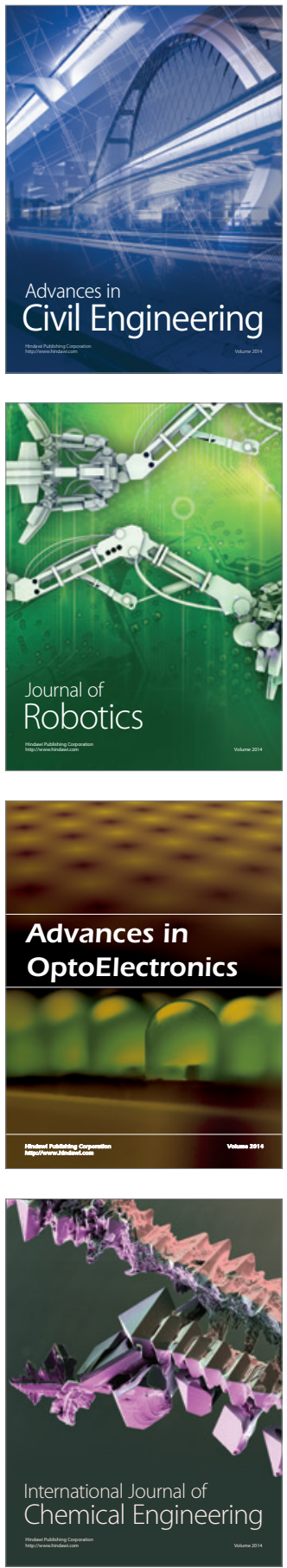

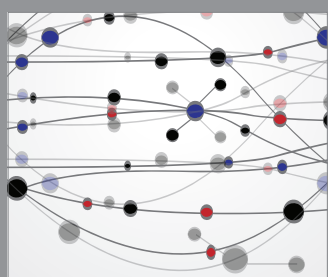

The Scientific World Journal

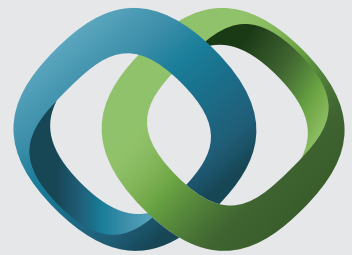

\section{Hindawi}

Submit your manuscripts at

http://www.hindawi.com
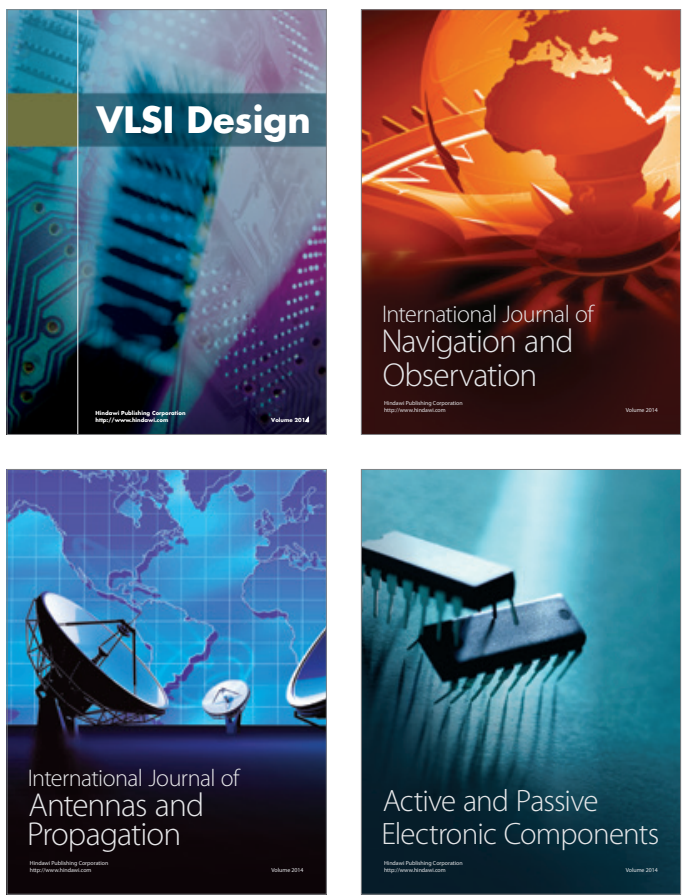
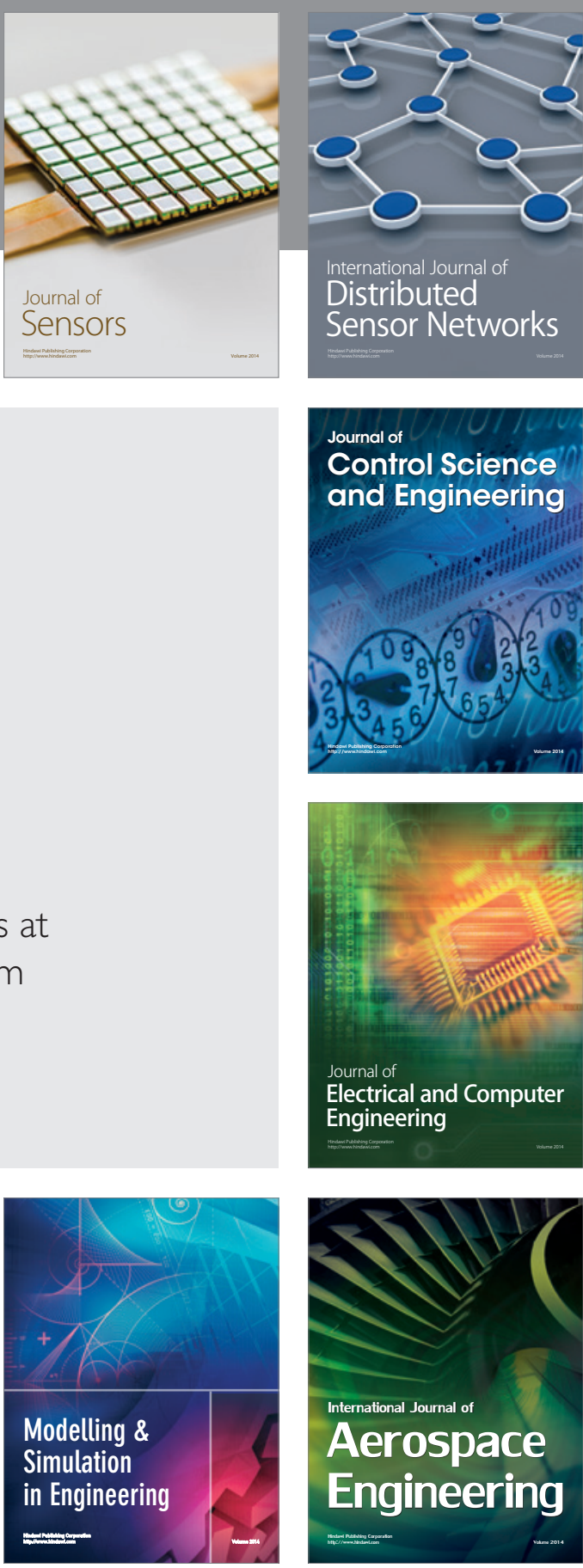

International Journal of

Distributed

Sensor Networks

Journal of

Control Science

and Engineering
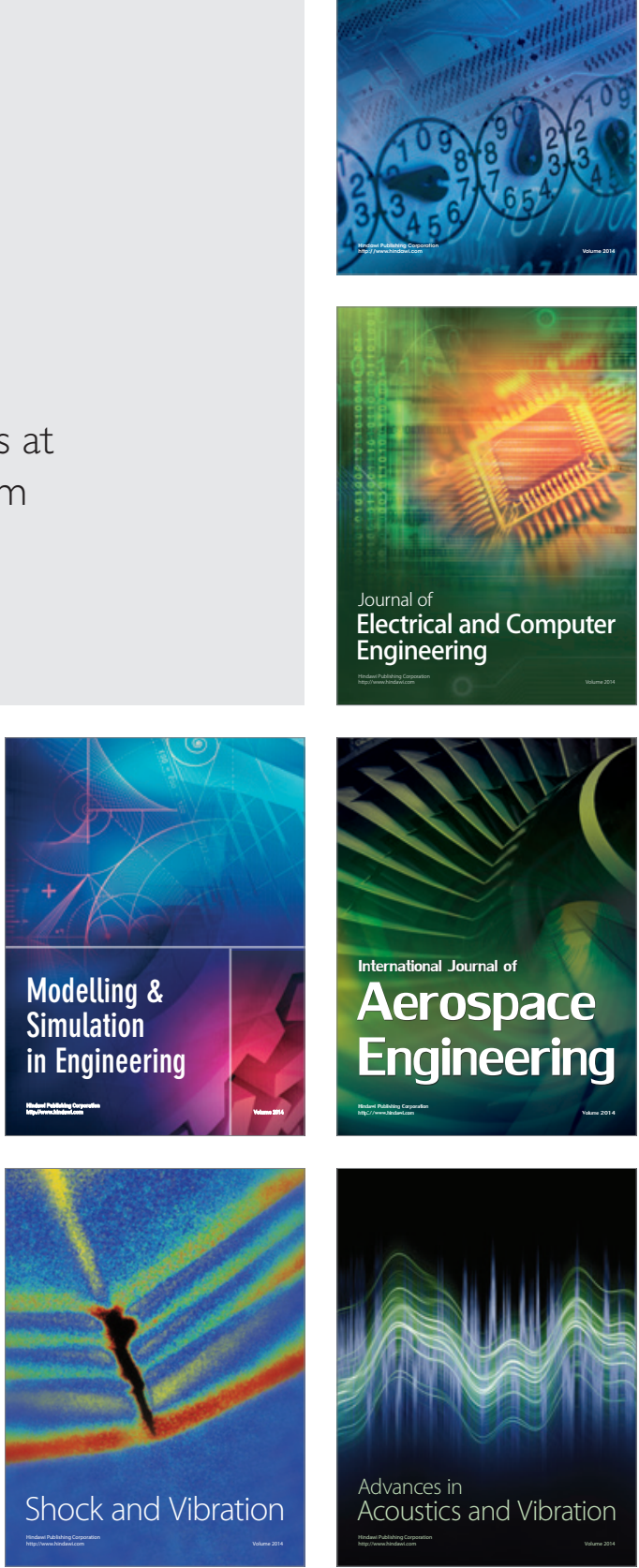